\title{
DỨBLIN
}

Technological University Dublin

ARROW@TU Dublin

Articles

School of Electrical and Electronic Engineering

2017

\section{Adaptive Linear Prediction for Optimal Control of Wind Turbines}

Mahinsasa Narayana

University of Moratuwa, Sri Lanka, mahinsasa@uom.lk

Keith Sunderland

Technological University Dublin, keith.sunderland@tudublin.ie

Ghanim Putrus

University of Northumbria at Newcastle, ghanim.putrus@northumbria.ac.uk

See next page for additional authors

Follow this and additional works at: https://arrow.tudublin.ie/engscheleart2

Part of the Electrical and Computer Engineering Commons

\section{Recommended Citation}

Narayan, M., Sunderland, K., Putrus, G., Conlon, M. (2017). Adaptive linear prediction for optimal control of wind turbines. Renewable Energy, vol. 113, pg. 895-906. doi:10.1016/j.renene.2017.06.041

This Article is brought to you for free and open access by the School of Electrical and Electronic Engineering at ARROW@TU Dublin. It has been accepted for inclusion in Articles by an authorized administrator of ARROW@TU

Dublin. For more information, please contact arrow.admin@tudublin.ie, aisling.coyne@tudublin.ie, gerard.connolly@tudublin.ie.

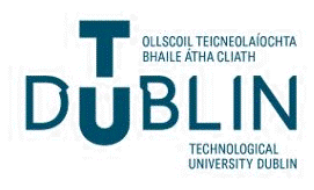




\section{Authors}

Mahinsasa Narayana, Keith Sunderland, Ghanim Putrus, and Michael Conlon

This article is available at ARROW@TU Dublin: https://arrow.tudublin.ie/engscheleart2/180 


\title{
Adaptive Linear Prediction for Optimal Control of Wind Turbines
}

\author{
Mahinsasa Narayana ${ }^{(1)}$ (mahinsasa@uom.lk) \\ Keith M. Sunderland ${ }^{(2)}$ (keith.sunderland@ dit.ie)* \\ Ghanim Putrus $^{(3)}$ (ghanim.putrus@ @orthumbria.ac.uk) \\ Michael F. Conlon ${ }^{(2)}$ (michael.conlon@ dit.ie) \\ (1) University of Moratuwa, Sri Lanka \\ (2) Dublin Institute of Technology, Ireland \\ (3) Northumbria University, UK \\ * Corresponding Author
}

\begin{abstract}
In order to obtain maximum power output of a Wind Energy Conversion System (WECS), the rotor speed needs to be optimised for a particular wind speed. However, due to inherent inertia, the rotor of a WECS cannot react instantaneously according to wind speed variations. As a consequence, the performance of the system and consequently the wind energy conversion capability of the rotor are negatively affected. This study considers the use of a time series Adaptive Linear Prediction (ALP) technique as a means to improve the performance and conversion efficiency of wind turbines. The ALP technique is introduced as a real time control reference to improve optimal control of wind turbines. In this study, a wind turbine emulator is developed to evaluate the performance of the predictive control strategy. In this regard, the ALP reference control method was applied as a means to control the torque/speed of the emulator. The results show that the employment of a predictive technique increases energy yield by almost $5 \%$.
\end{abstract}

\section{Keywords}

Wind energy conversion systems; Wind turbine; Linear adaptive prediction; Power mapping technique; Wind speed sensor technique; Wind speed estimation.

\section{Introduction}

Growth in wind energy is at an unprecedented level. At the end of 2015 there was in excess of $433 \mathrm{GW}$ of installed capacity (globally) [1], with wind energy supplying $3.7 \%$ of global electricity [2]. Indeed, the Global Wind Energy Council (GWEC) in their 2015 annual update, reported that the average annual growth (year-on-year) in wind energy capacity is $22 \%$ since 2000 [1]. The International Energy Agency (IEA) further emphasise the potential for wind energy by suggesting that $15-18 \%$ of global electricity will come from wind power by 2050 [2]. The growing trends in wind energy technology are motivating researchers to work in this area with the aim of optimising the energy extraction form the wind and the injection of quality power into the grid [3]. This growth is partly due to the technological improvement of wind turbines, which has led to significant decrease of wind power cost, allowing the energy source to compete with conventional generation methods [4]. 
Although the operational speed at which WECS generate can be fixed or variable, variable wind speed turbines - in attempting to maintain a constant rotational speed to wind speed ratio - offer the only means to maximise the energy extracted from the wind [5]. While any generator can operate at a fixed or variable speed [4], the permanentmagnet synchronous generators (PMSG) have been found to be superior owing to their advantages of higher efficiency, higher power density, lower maintenance costs and better grid compatibility [6]. Wind speeds are continuously varying and although the rotor of a WECS is required to drive at an optimal rotor speed for a particular wind speed, it cannot be instantaneously changed due to the moment of inertia of the rotating parts. Therefore, the response of the rotor to wind speed variations affects the performance of the system.

There are many different maximum power point tracking (MPPT) control strategies [3]. These range from optimising the relationships among various system parameters i.e. optimum relationship-based (ORB) control [3], to optimising torque through an optimal torque (OTC) control [4]. Others seek to maximise power efficiency (tip-speed-ratio (TSR) control), where the MPPT strategy is extremely reliant on the accuracy of the wind speed [7], whereas in the perturb \& observe $(P \& O) /$ Hill-climb search (HCS) control strategy, the necessity of speed sensors is eliminated [8].

In this paper, time series linear predictions are considered as a means to improve the optimum control performance of wind turbines. Real time control parameters are adjusted to achieve the optimum operating point of the system by considering the future value of the control reference signals. Time series prediction through an adaptive linear prediction method is evaluated by using measured wind data is proposed in this regard. The introduction of predicted wind speed estimates facilitates a prediction (forecast) of the control reference point for power harnessing enhancement. Such an approach can be incorporated into any type of MPPT technique. The paper therefore, proposes possible energy harvesting improvements through an optimised wind sensor method, in conjunction with power or torque mapping techniques, which are commonly used for many commercial wind turbines already.

Wind speed-time series data typically exhibit autocorrelation, which can be defined as the degree of dependence on preceding values. Autocorrelated time series models are commonly used for the wind speed prediction [9] In an autocorrelated wind speed-time series, the value of wind speed in any one time step is strongly influenced by the values in previous time steps. Based on a number of historical data, pattern identification and parameter estimation, model checking are utilized to make a mathematical model of the time series data prediction[10]. Statistical models have been used for time series analysis and these models can be divided as follows: autoregressive models (AR), moving average models (MA), auto regressive moving average models (ARMA) and auto regressive integrated moving average model (ARIMA). The seasonal ARIMA model presents a better sensitivity to the prediction of wind speed. However, when the number of training vectors is increased for the ANN model, its performance would be improved [11].

The utilisation of artificial neural networks (ANN) offer promising techniques for predicting time series wind data [9]. Prediction performance of ANN is superior to the AR model and capable to use for multi-step prediction [12]. Alternatively, fuzzy logic control can be implemented. Fuzzy logic controllers such as the multivariable 
predictive control (FMMPC) presented in [13] offer a methodology to satisfy the double objective of simultaneously regulating for both rotor speed and electrical power [13]. Other techniques include metaheuristic optimization techniques such as a fuzzy controller using particle swarm optimi sation [14]. Indeed, in the context of synergising techniques into control systems applicable to wind energy, the potential for ANN is enhanced through the application of fuzzy logic. In this regard and as reported by Sideratos and Hatziagyriou[14], satisfactory results can be derived through this combination. .

The focus of this paper is to establish the potential for MPPT enhancement though the integration of a wind speed input reference model. In this regard, an Adaptive Linear Prediction methodology is employed. This method, as will be established in section 2, displays good characteristics in the context of turbulent wind conditions.

A wind turbine emulator is subsequently developed to evaluate the effectiveness of linear predictions for optimal controllability of small wind turbines using the ALP prediction algorithm. Digital Signal Processing (DSP) techniques were used to control the wind turbine emulator. A typical wind speed sensor method and in conjunction with power mapping through a wind speed sensorless method were also evaluated with and without time series prediction techniques. The results suggest that the proposed control reference point prediction methodology offers performance improvement possibilities for WECS. In the context of the methodology proposed in this paper, a 5\% increase was achieved.

The structure of the paper is as follows. Section 2 discusses adaptive linear prediction as a methodology to derive time series predictions for wind speed and in this regard, a relevant methodology for real-time predictions is chosen. Section 3 outlines the characteristics of a PM WECS system followed by a study in section 4 that incorporates a comparative analysis of both the wind speed sensor and a power torque mapping consideration with and without linear wind speed predictions. Section 5 explains how the system was compiled experimentally with sections 6 and 7 detailing the results and acquired conclusions respectively.

\section{Adaptive linear prediction}

If time series data of a signal exhibits autocorrelation, an adaptive filter in prediction mode can be exploited for time series linear predictions. In Figure 1, the input signal, delayed by $\Delta$ time unit, is fed into an adaptive filter. The non-delayed input serves as the desired signal for this adaptive filter. An error signal, $e(n)$, is computed as $e(n)=d(n)-y(n)$, which measures the difference between the output of the adaptive filter $[y(n)]$ and the desired signal $[d(n)]$. The filter weights adapts and converges to produce a best least-squares estimation of the delayed signal to minimize the error signal[ $e(n)]$ [15].

In this study the coefficients $[W(n)]$ of the adaptive filter in predictive mode are also estimated by the Recursive Least Squares (RLS) algorithm, which is more suitable for real-time applications [16]. The optimal 'weightings' are copied into a "slave filter" in which input is non-delayed signal and output is a best least squares prediction of the input $\Delta$ time units into the future. 


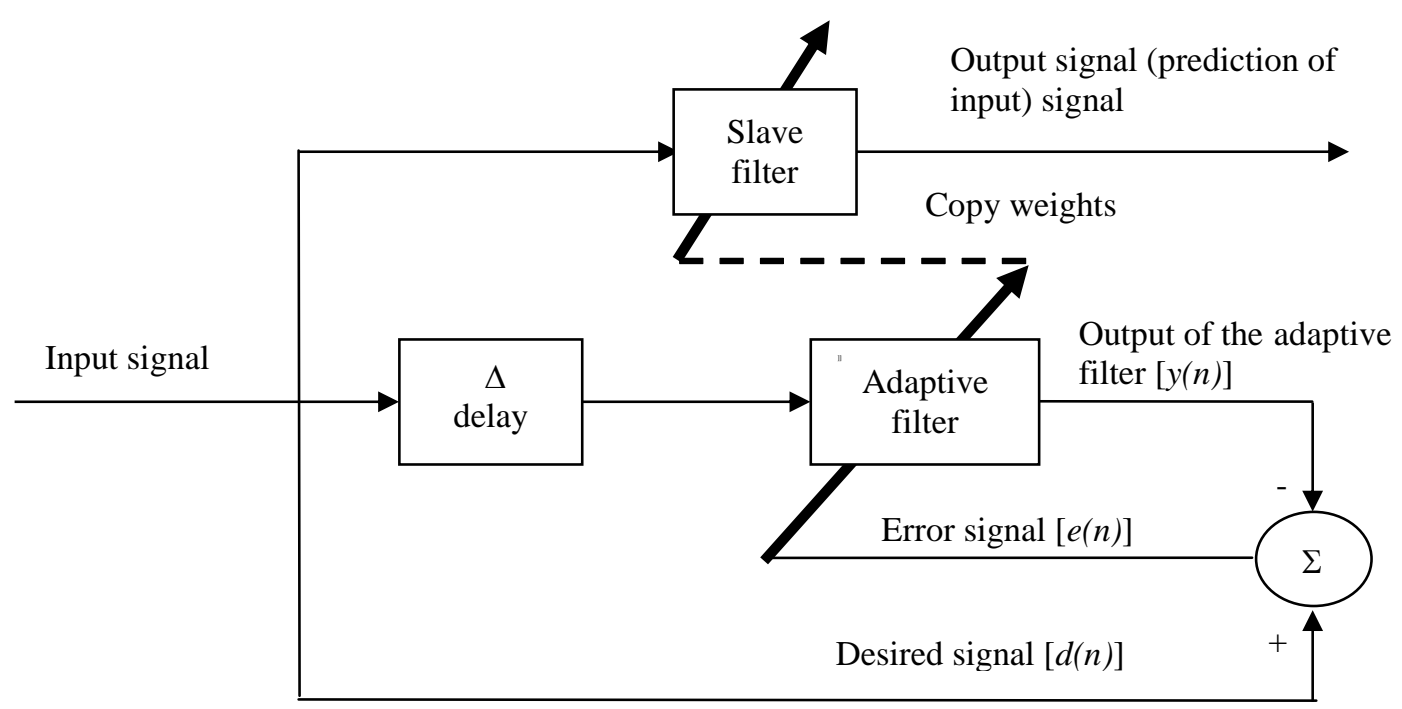

Figure 1: The Adaptive linear prediction technique

Thus in the context of this paper, an ALP technique through an RLS methodology (ALP-RLS) is employed as the control parameter for MPPT. The selected parameters for the ALP-RLS filter in predictive mode include, a filter order of 8, a forgetting factor of 1 and initial value of filter weightings as 0 , where the forgetting factor (0 to 1) specifies how quickly the filter "forgets" a past sample [15]. The measured (real) wind data are used to investigate the effectiveness of the ALP-RLS predictions of wind speed data. In order to measure the accuracy of predictions, the root mean square error (RMSE) was used.

$\mathrm{RMSE}=\sqrt{\frac{1}{n} \sum_{i=1}^{n}\left(v_{i}-v_{i p}\right)^{2}}$

where $n$ is the total number of data points (5000), $v_{i}$ are actual values of wind speeds and $v_{i p}$ are the predicted values for $v_{i}$.

The root mean square error (RMSE) $\mathrm{m} / \mathrm{s}$ of predictions for $1 \mathrm{~s}$ logging time is considered in terms of actual wind data collected at Blyth, UK is 0.345 . Figure 2 illustrates a box-plot comparison between the recorded wind speed and the ALP-RLS derived predictions. The RMSE of the ALP-RLS prediction methodology is $0.3458 \mathrm{~m} / \mathrm{s}$ or $14 \%$ of the mean wind speed observed over the sample $(2.44 \mathrm{~m} / \mathrm{s})$ 


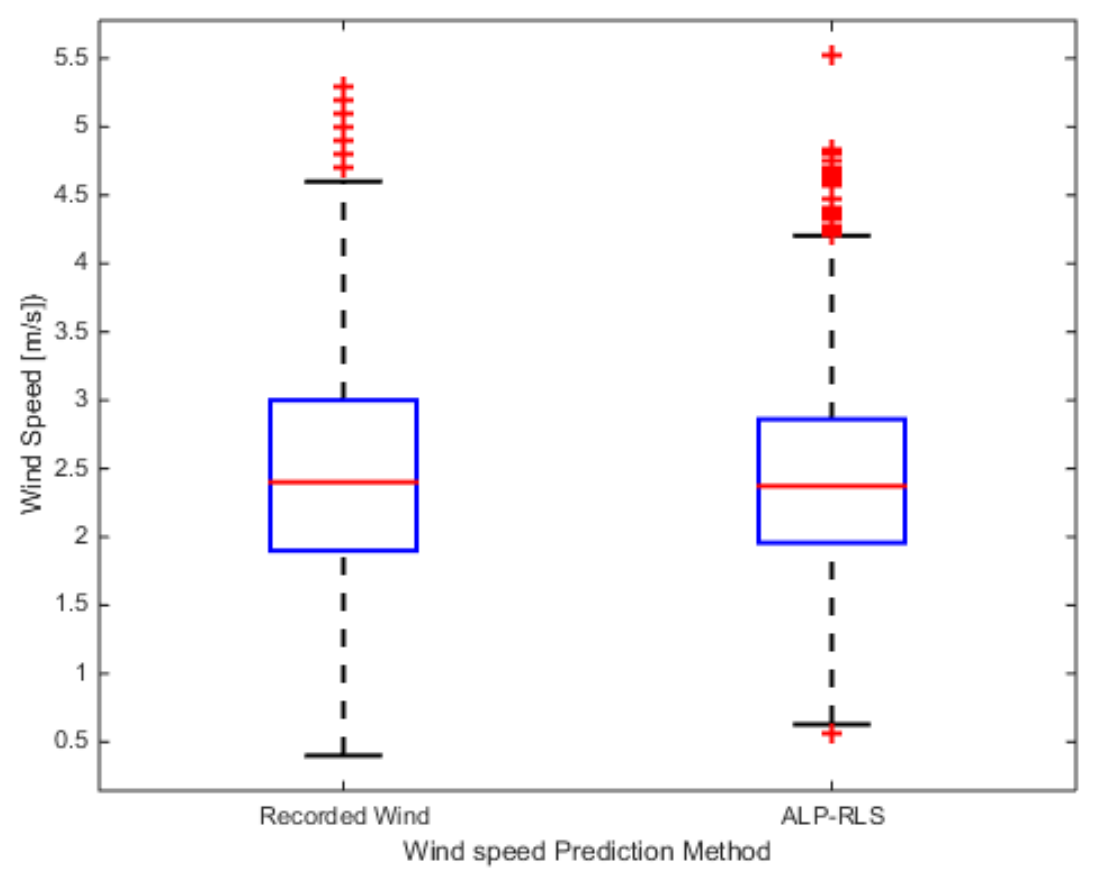

Figure 2: ALP-RLS box-plot comparison in terms of recorded wind speed sample

\section{Wind Rotor Model}

\subsection{Aerodynamic characteristics of the wind rotor}

Based on the wind turbine aerodynamic behaviour, the wind rotor converts only a portion of the kinetic energy contained in the wind [17]; that is:

$P_{a}=\frac{1}{2} \cdot \rho \cdot \pi \cdot R_{r}^{2} \cdot v^{3} \cdot C_{p}$

where $P_{a}$ is the captured power by the wind rotor, $R_{r}$ is the radius of the wind rotor, $\rho$ is the air density and $v$ is the speed of the incident wind.

The proportion of the useful power is defined by the power coefficient $C_{p}$, which for a given wind turbine rotor, depends on the pitch angle of the wind rotor blades and on the tip speed ratio $(\lambda)$; defined as:

$\lambda=\frac{\omega \cdot R_{r}}{v}$

where $\omega$ is the rotational speed of the rotor.

The wind rotor aerodynamic characteristics are represented by the $C_{p}-\lambda$ relationship. In the context of variable speed wind turbines; when wind speed varies, the wind turbine rotor speed should be adjusted proportionally to maintain optimum tip speed ratio for maximum power extraction. Using equation (2) the aerodynamic torque $\left(T_{a}\right)$ developed by a wind rotor can be obtained as follows: 
$T_{a}=\frac{1}{2} \cdot \rho \cdot \pi \cdot R_{r}^{3} \cdot v^{2} \cdot \frac{C_{p}}{\lambda}$

$T_{a}=\frac{1}{2} \cdot \rho \cdot \pi \cdot R_{r}^{3} \cdot v^{2} \cdot C_{t} \quad$ where $C_{t}=\frac{C_{p}}{\lambda}$

where $C_{t}$ is the torque coefficient and $T_{a}$ is the Aerodynamic torque of wind rotor. The $C_{p} \& C_{t}-\lambda$ relationship of the wind turbine, which is considered in this study, is shown in Figure 3.

For wind turbine-generator systems with a gearbox, the aerodynamic torque can be expressed as $K T_{a}$, where $K$ is the gear ratio of the gearbox.

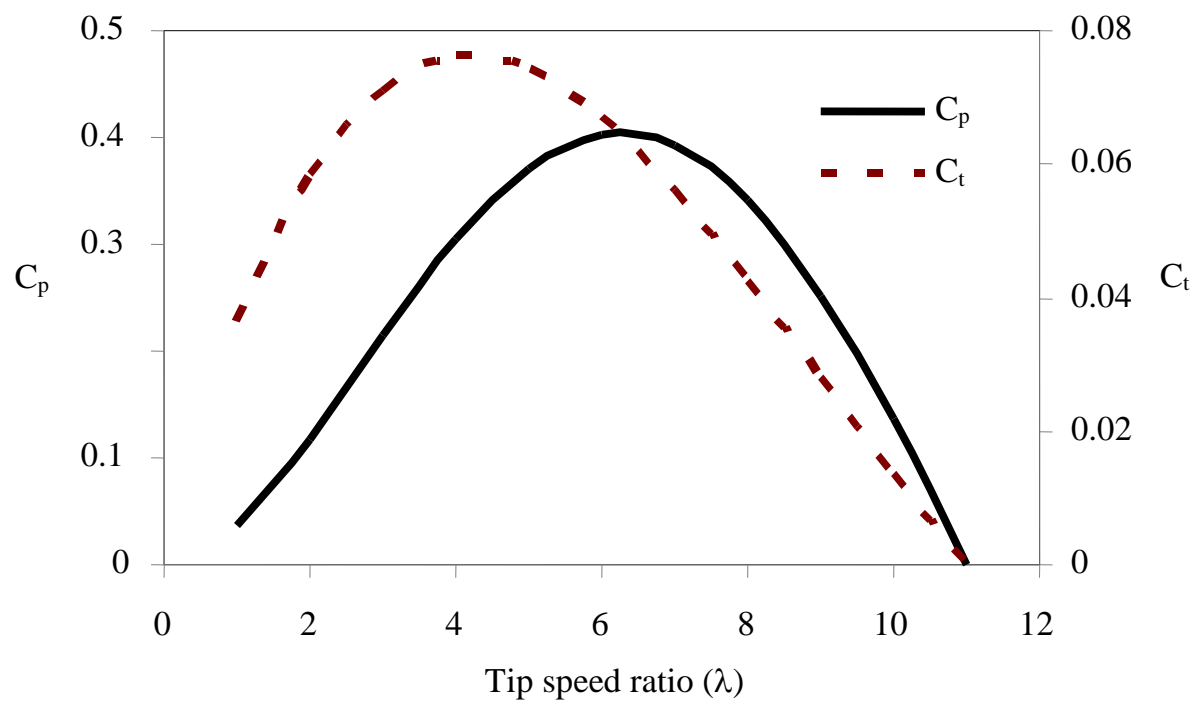

Figure 3: $C_{p} \& C_{t}-\lambda$ relationship of the wind turbine

\subsection{Electromagnetic torque of the generator}

Generally, three phase permanent magnet generators (PMGs) are used for small scale wind turbines. In this system, a three-phase bridge rectifier is used to convert a.c. to d.c. and it is used for battery charging or inverting again to a.c. for grid connection. Configuration of the small wind power system is shown in Figure 4. Equivalent d.c. circuit for a PMG and a three phase rectifier is shown in Figure 5; adapted from [18]. 


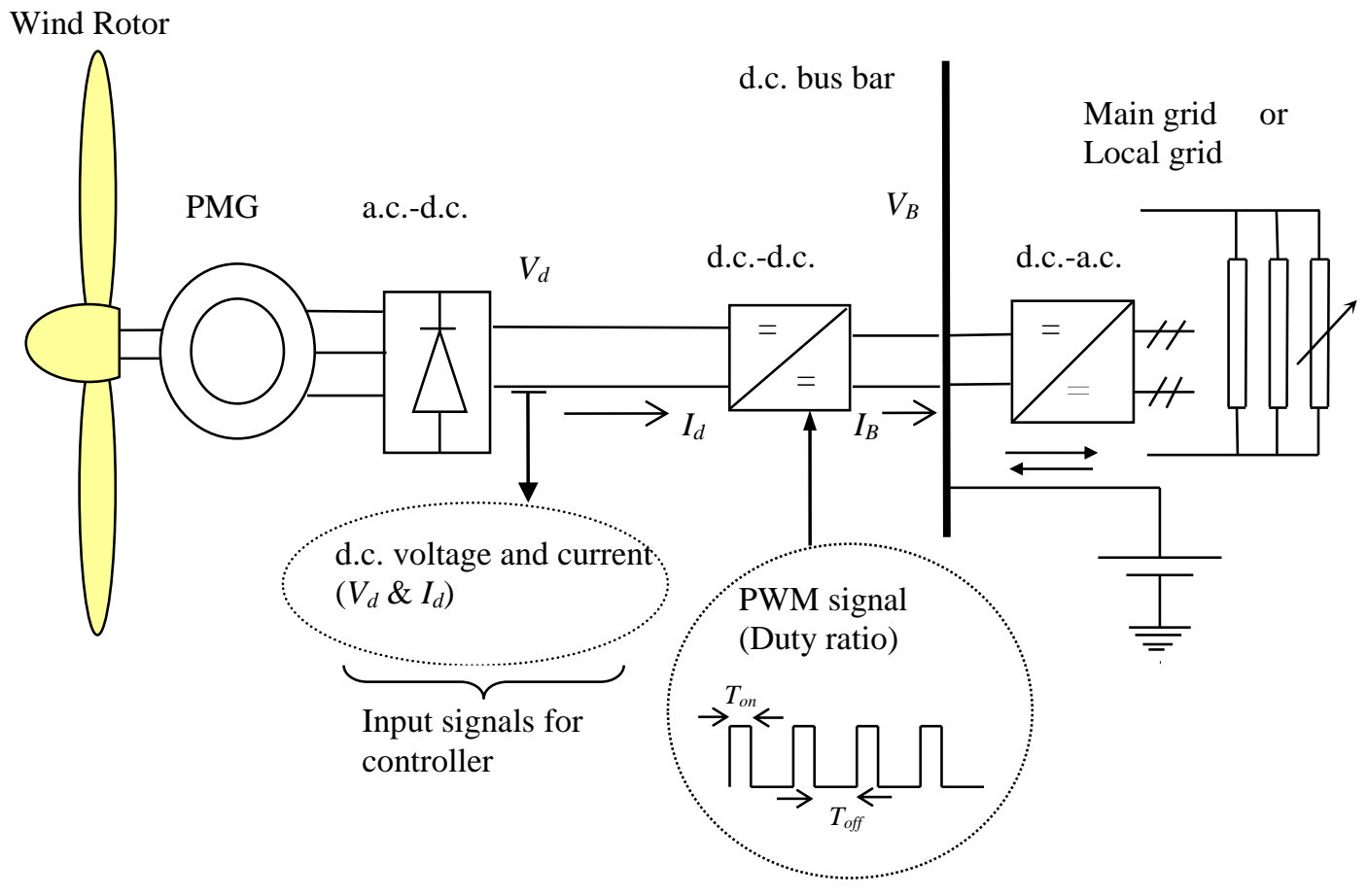

Figure 4: Configuration of the small wind power system

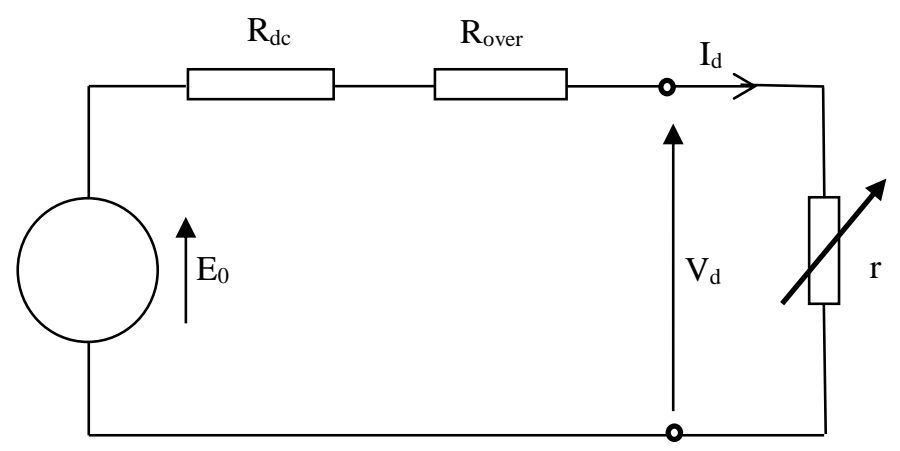

Figure 5: Equivalent d.c. circuit of a PMG

For an equivalent d.c. circuit of a PMG (Figure 5) as it is incorporated with a three phase rectifier, the effective armature resistance $\left(R_{d c}\right)$ is approximately twice the phase resistance [18]. i.e.

$R_{d c} \approx 2 R_{p h}$

The overlap resistance is given by [18],

$R_{o v e r}=\frac{3}{\pi} \omega_{s} L_{p h}$

where $\omega_{s}=p \omega, L_{p h}$ is the phase inductance, $\omega_{\mathrm{s}}$ is the rotational speed of electric field and $p$ is the number of pole pairs. 
Then, the wind turbine terminal d.c. voltage is;

$V_{d}=E_{0}-I_{d}\left(R_{d c}+R_{o v e r}\right)$

Let $R=R_{d c}+R_{\text {over }}$

Therefore; $E_{0}=V_{d}+I_{d} R$

$k^{\prime} \omega=V_{d}+I_{d} R, \quad$ as $E_{0}=k^{\prime} \omega$

Torque is derived by electric power at the armature for loss-less operation $\left(P_{E}=E_{0} I_{d}\right)$ and rotational speed $(\omega)$.

$$
T_{e}=\frac{P_{E}}{\omega}=\frac{E_{0} I_{d}}{\omega}=\frac{k^{\prime} \omega I_{d}}{\omega}=k^{\prime} I_{d}
$$

The generator torque is a function of generator current $\left(I_{d}\right)$, magnetic flux linkage and number of pole pairs [19]. For a particular generator $k^{\prime}$ is a fixed parameter depending on magnetic flux linkage and number of pole pairs. Therefore electromagnetic torque of a generator $\left(T_{e}\right)$ can be varied by controlling the current.

\section{Optimal Control of WECSs}

\subsection{Predictive control of wind turbines}

According to wind speed variations, a quick response of wind turbine rotor speed is not practicable/possible due to the moment of inertia of rotating parts. Therefore exact control is unrealistic with control reference point estimation by real time parameters. If future reference wind turbine rotor speed is predicted, appropriate rate of change of wind rotor speed $(d \omega / d t)$ can be established to achieve an optimal operating point after the predicted time step. The predictive control criterion is presented in Figure 6.

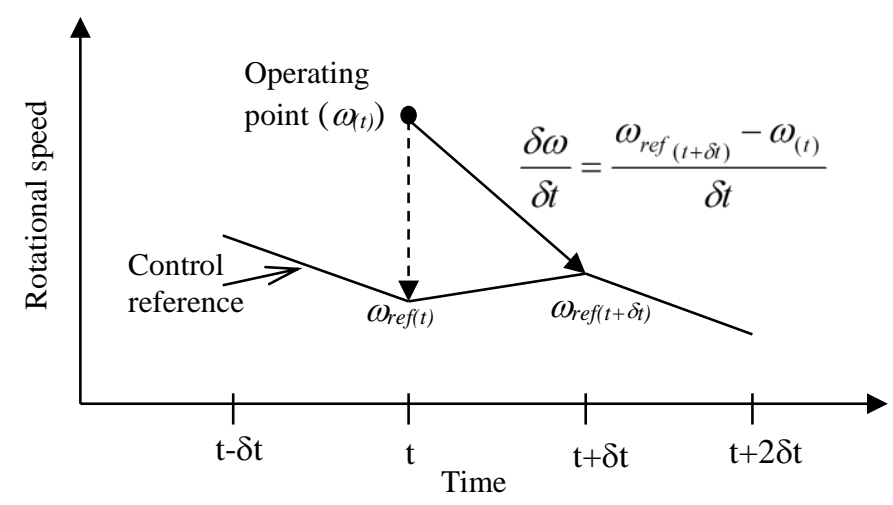

Figure 6: Predictive control criterion 
According to Figure 5, the required rate of change of the rotor rotational speed ( $\delta \omega / \delta t)$ to achieve the optimal operating point after predicted time step $(\delta t)$ can be derived as follows;

$$
\frac{\delta \omega}{\delta t}=\frac{\omega_{r e f(t+\delta t)}-\omega_{(t)}}{\delta t}
$$

Torque interaction of the wind rotor and the generator can be expressed as;

$T_{e}=K T_{a}-\frac{d \omega}{d t} J-T_{f}$

where $J$ is momentum of inertia of rotating parts, $T_{f}$ is torque due to friction losses.

The electromagnetic torque of a generator $\left(T_{e}\right)$ is controllable. Aerodynamic torque of the wind rotor $\left(T_{a}\right)$ and torque due to friction $\left(T_{f}\right)$ depend on uncontrollable external parameters (as well as; $T_{f}<<T_{a}$ and $T_{f}<<T_{e}$ ). Therefore the rate of change of rotational speed $(d \omega / d t)$ can be controlled by varying electromagnetic torque of the generator $\left(T_{e}\right)$ and it is expressed as follows;

$$
\frac{d \omega}{d t}=\frac{K T_{a}-T_{e}-T_{f}}{J}
$$

The response time of rotor speed variation (from $\omega_{1}$ to $\omega_{2}$ );

$$
t=\int_{0}^{t} d t=\int_{\omega_{1}}^{\omega_{2}} \frac{J}{K T_{a}-T_{e}-T_{f}} d \omega
$$

The required maximum time ahead prediction is dependent on the response time of the system. However prediction error will increase with size of the time step [20]. In this study prediction time step is lower than the response time of the system. If prediction time step of reference is more than response time of the system, optimal control will not be realised.

\subsection{Control strategies}

Different types of power electronic converter topologies are available for wind turbines and these implement different control scheme optimality [21]. The optimum operating point of a wind turbine system is usually determined in order to achieve the highest aerodynamic efficiency of the wind rotor. Generally, a controller that employs a wind speed sensor (or in some cases, sensor-less control) is used to control the wind turbine. In systems that employ wind speed sensors, the wind sensor provides the turbine speed reference to the controller. The reference control point is evaluated by using equations (6), (7) and $C_{p}-\lambda$ curve (see Figure 3 ). This reference is compared with the actual turbine speed. A control diagram of wind speed sensor method is shown in Figure 7. A PI controller is used for this comparison study. Gains of the PI controller were manually adjusted by considering Zieger-Nichols PI tuning rules for step change of reference 
rotational speed[22]. For the PI controller, selected proportional gain $(\mathrm{kp})$ is 0.052 and integral gain (ki) is 0.324 .

In the sensor-less control technique, anemometry is not employed to provide the wind speed information; hence, it is essential to estimate the wind speed by using predetermined system characteristics. At steady state $(d \omega / d t=0)$ and $T_{e} \approx T_{a}$ wind speed can be estimated by the generator outputs. Predetermined power output in terms of output d.c. voltage curves are correlated with corresponding wind speed values. This can be described by equations (9), (13), (14) and the $C_{t}-\lambda$ curve (see Figure 4). Generally, the generator speed (or output d.c. voltage) and power (or torque) mapping techniques are used to estimate the reference control point [23]. At steady state, power output versus output d.c. voltage curves of the wind turbine are presented in Figure 8. In the power mapping method, estimated control reference is compared with the measured parameter.

The control diagram of power or torque mapping method is shown in Figure 9. For this paper, a comparative study was performed to evaluate performances of the wind speed sensor method and the power mapping method with and without linear predictions. Test results are presented in the section 6 .

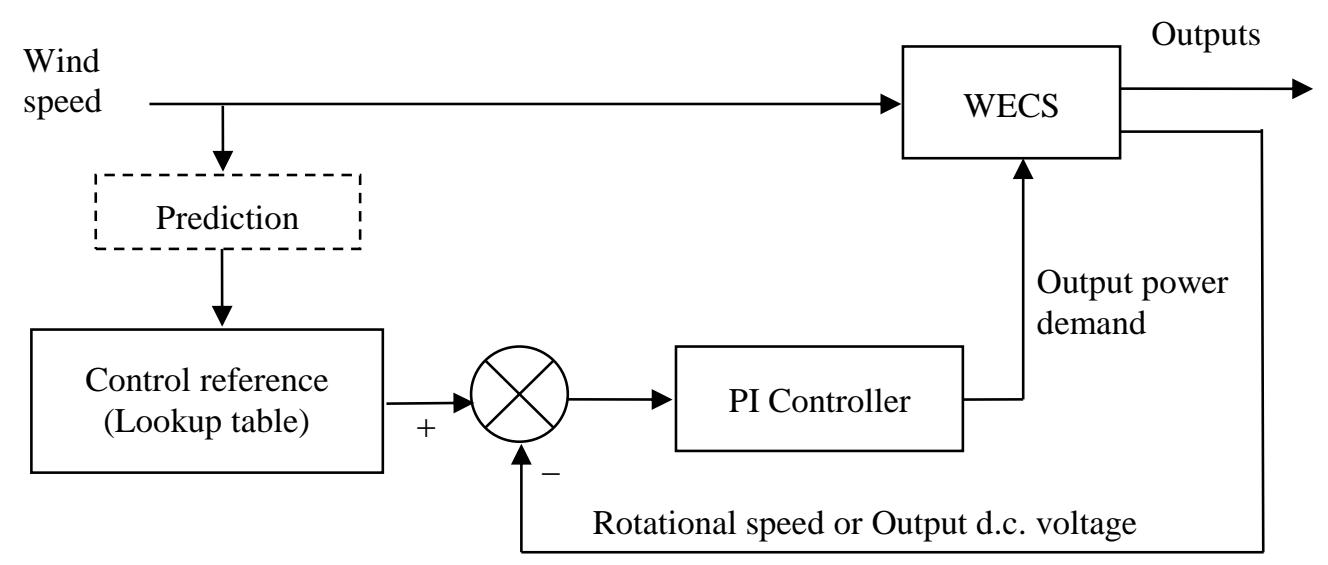

Figure 7: Control diagram of wind speed sensor method 


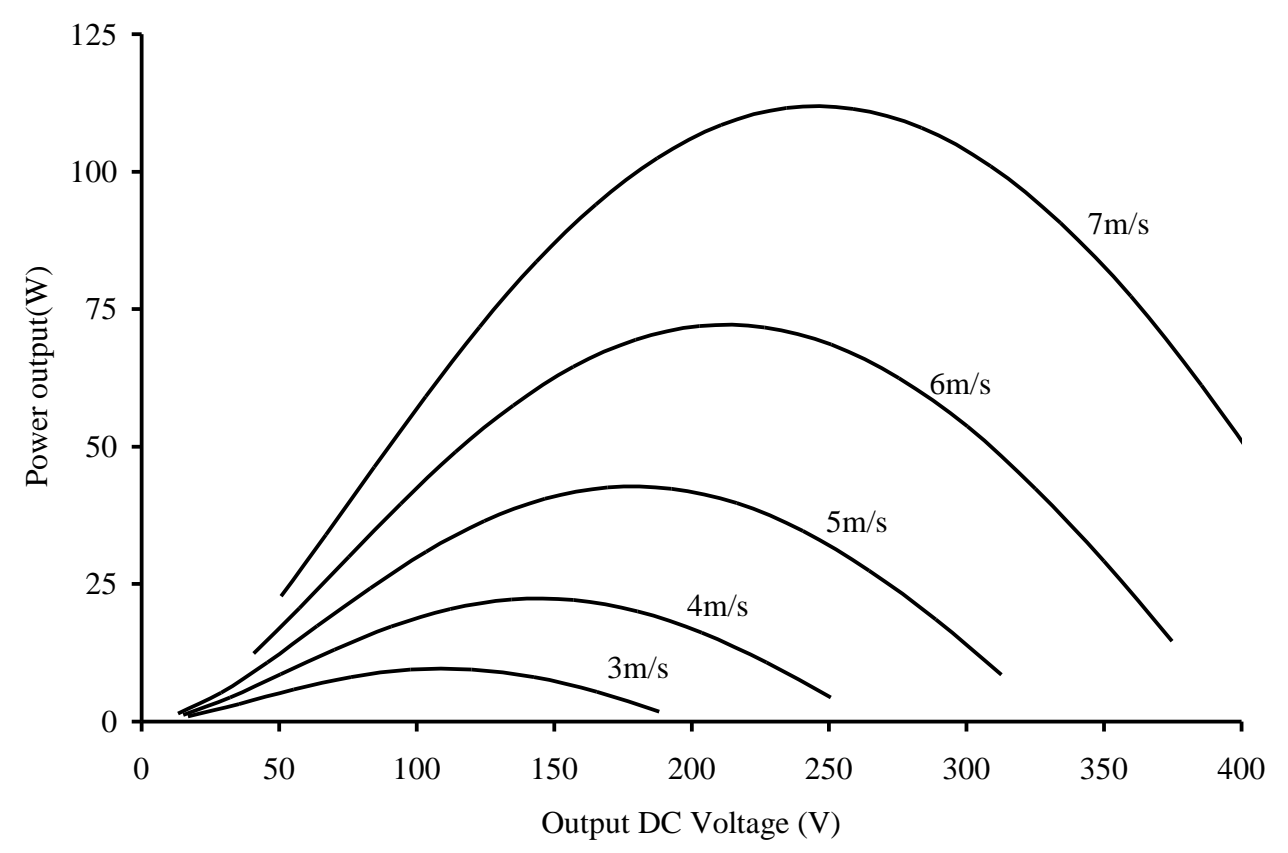

Figure 8: Power output versus output d.c. voltage curves

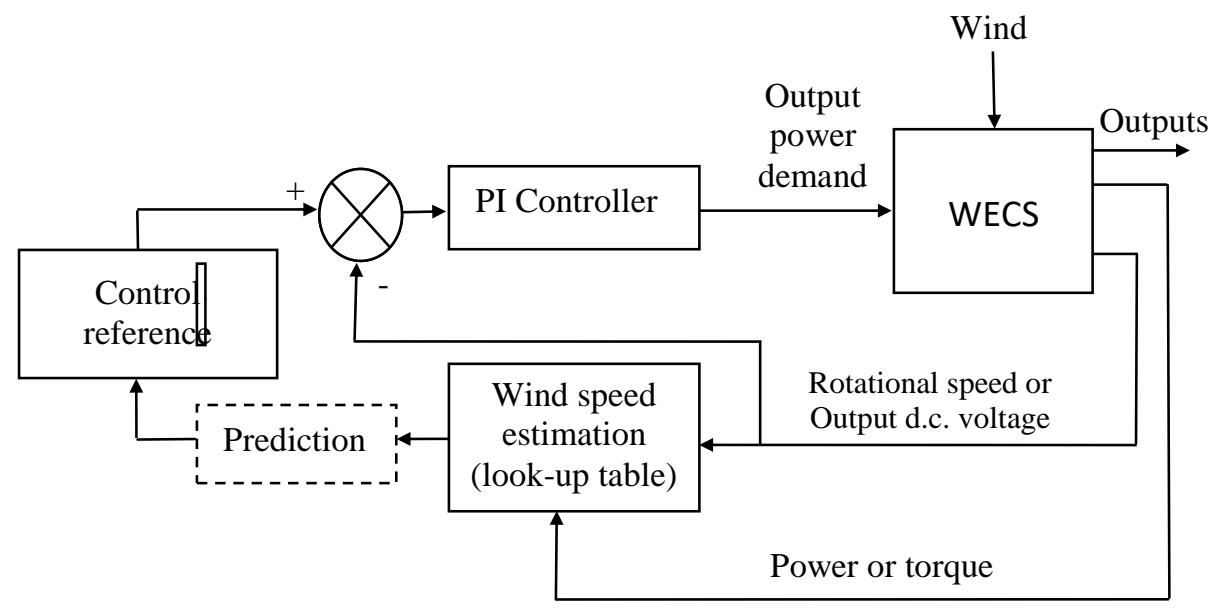

Figure 9: Control diagram of power or torque mapping method

\section{Experimental Setup}

\subsection{The Wind turbine emulator}

The wind turbine emulator developed in this study is a prime mover (shunt motor), which has the torque-speed characteristics of a real wind rotor and driven by time series wind speed data. The prime mover is coupled with a suitable generator to represent a WECS. A wind turbine emulator was introduced in this study to evaluate and compare the performance of different control strategies of WECSs. This is necessary, since the performance of a real wind turbine is subjected to variable wind conditions. Therefore, it is more difficult to carry out in practice. The performance comparisons of each control system were evaluated for the same time series wind speed data set under the same wind condition, which were supplied to the wind turbine emulator. Real time torque and rotational speed measurements of the system are required for controlling the prime 
mover according to the pre-loaded real wind rotor characteristics and wind speed data. In addition, this allows control of the rotational speed of a d.c. shunt motor by an external control signal. This system was adapted as a real time wind turbine emulator with the help of Digital Signal Processing (DSP) techniques based on a dSPACE DS1103 PPC control and data acquisition board [24]. The wind turbine emulator was operated with a $1 \mathrm{~s}$ logging time of measured wind speed data to imitate a real situation. The effects of coning and flapping of the rotor blades are assumed to be negligible and hence were not considered in this wind turbine emulator. Also for the analysis considered here, the tower shadow effect is negligible [25][26]. As this study is carried out for a comparison work based on small-scale WECS (SS-WECSs), the effects due to the tower shadow and cnning \& flapping deformation of the wind rotor blades can be ignored. Normally in SS-WECSs, the wind rotor is directly coupled to the generator by a short shaft. The power transmission drive train configuration of SS-WECSs is similar to the drive train of the motor-generator set used in the proposed emulator and then drive trains are not required to be separately model by this wind turbine emulator.

In this research study, the model reference control criterion is proposed to control the emulator[26]. The Reference model is the mathematical model of the wind rotor and the plant model is the "Feedback" Torque \& Speed control module [27]. As non-linear characteristics of the "Feedback" control module, the Nonlinear Autoregressive Moving Average (NARAM) model [28] is introduced to characterize the integrated system of the "Feedback" Torque $\&$ Speed Control module and the d.c. shunt motor.

\subsection{Model Reference Control}

A d.c. shunt motor is connected to the "Feedback" Torque \& Speed control module, which allows the rotational speed to be controlled by an external signal. The model reference control strategy was used to control the d.c. shunt motor through the "Feedback" Torque \& Speed control module. The reference model (implanted through the digital signal processing (DSP) board) calculates the required output reference of the plant according the emulated wind rotor characteristics. The model reference controller evaluates a suitable plant input based on the plant model with a feedback loop. The plant model therefore represents the plant input and output relationship. The concept of the model reference control strategy is presented in Figure 10 [29], with Figure 14 providing the context of where the feedback resides in the overall control strategy. In this system, the reference model is the wind rotor whilst the plant model is the d.c. shunt motor incorporated with the Torque \& Speed control module. A mathematical model of the wind rotor was used as the reference model. Modelling of the "Feedback" Torque \& Speed control module proved to be difficult to develop as parameters and specifications are unknown. Therefore, an empirical model, which is represented by an artificial neural network model (trained by the experimental data), of the d.c. shunt motor and the "Feedback" Torque \& Speed control module was considered to represent the plant model of this system. 


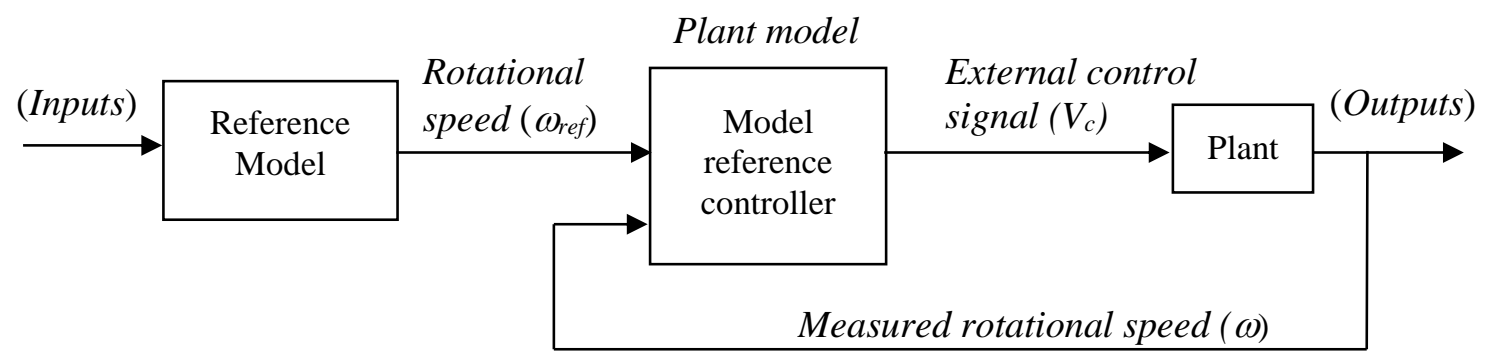

Figure 10: Concept of the model reference control strategy

The aerodynamic torque delivered by the wind rotor is described by equation (7). The dynamic aerodynamic torque is derived by applying a lead-lag filter transfer function to the static aerodynamic torque [30].

Rate of change of the rotational speed $(d \omega / d t)$ of the wind rotor can be expressed by considering the momentum of inertia of the wind rotor and torque interactions in the time domain. Therefore, real time reference rotational speed $\left(\omega_{r e f}\right)$ can be determined by integrating the rate of change of the rotational speed $(d \omega / d t)$ with relevant initial conditions.

Torque interactions of the wind rotor and the generator is described by the relationship of the aerodynamic torque developed by the wind rotor $\left(T_{a}\right)$, the electromagnetic torque of the generator $\left(T_{e}\right)$, the torque due to angular acceleration $(\dot{\omega} \cdot J)$ and the frictional torque $\left(T_{f}\right)$.

$T_{a}=\dot{\omega} . J+T_{e}+T_{f}$

The rotational speed at a time " $t$ " is subsequently provided as (by integrating equation $14)$

$\omega_{\text {ref }}=\int_{0}^{t}\left(\frac{T_{a}-T_{e}-T_{f}}{J}\right) \cdot d t$

where $J$ is the momentum of inertia of rotating parts, $T_{a}$ is the aerodynamic torque by the wind rotor, $T_{e}$ is the electromagnetic torque of generator and $T_{f}$ is the torque due to friction losses

The real time rotational speed and shaft torque are used to evaluate the reference rotational speed(s) for a given time series wind speed data. The reference wind rotor model during dynamic state is shown in Figure 11.

The wind rotor size for the wind turbine emulator was selected based on the maximum wind speed and the rating of the "Feedback" d.c. shunt motor (200W). The d.c. shunt motor should be capable to imitate the wind rotor by delivering the relevant power for the associated dynamic state $(d \omega / d t)$ and given wind speed. 


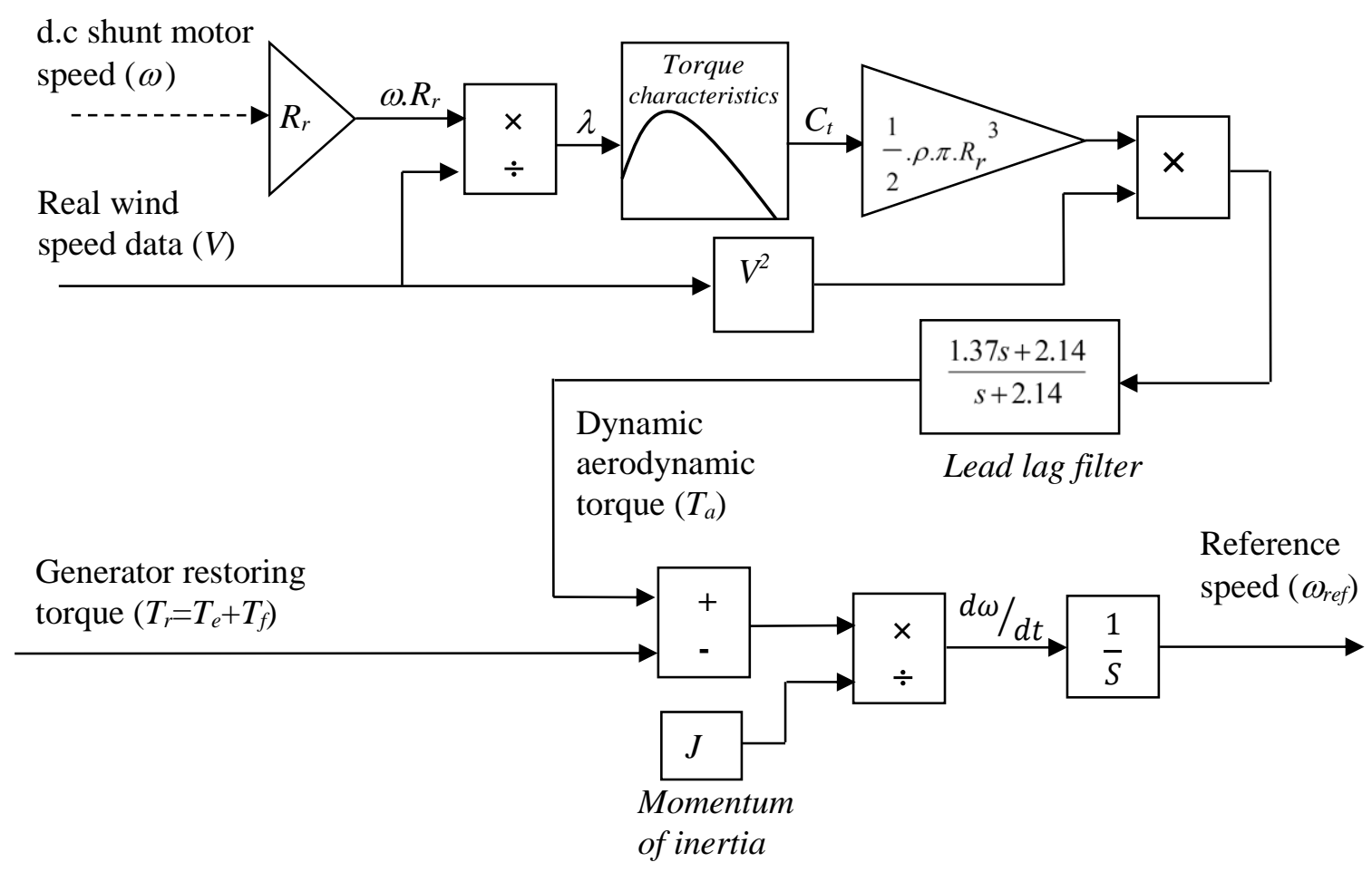

Figure 11: The wind rotor reference model

The "Feedback" Torque \& Speed Control module operates in speed control mode and this allows for demanding required rotational speeds by an external control input (0$10 \mathrm{~V})$. The real time rotational speed and torque of the d.c. shunt motor can be measured by two output signals (0-10V) from the "Feedback" Torque \& Speed Control module. These output signals were calibrated with a standard tachometer and a torque meter. The measured rotational speed and torque value versus the output signal voltage are shown in Figure 12 and 13 respectively.

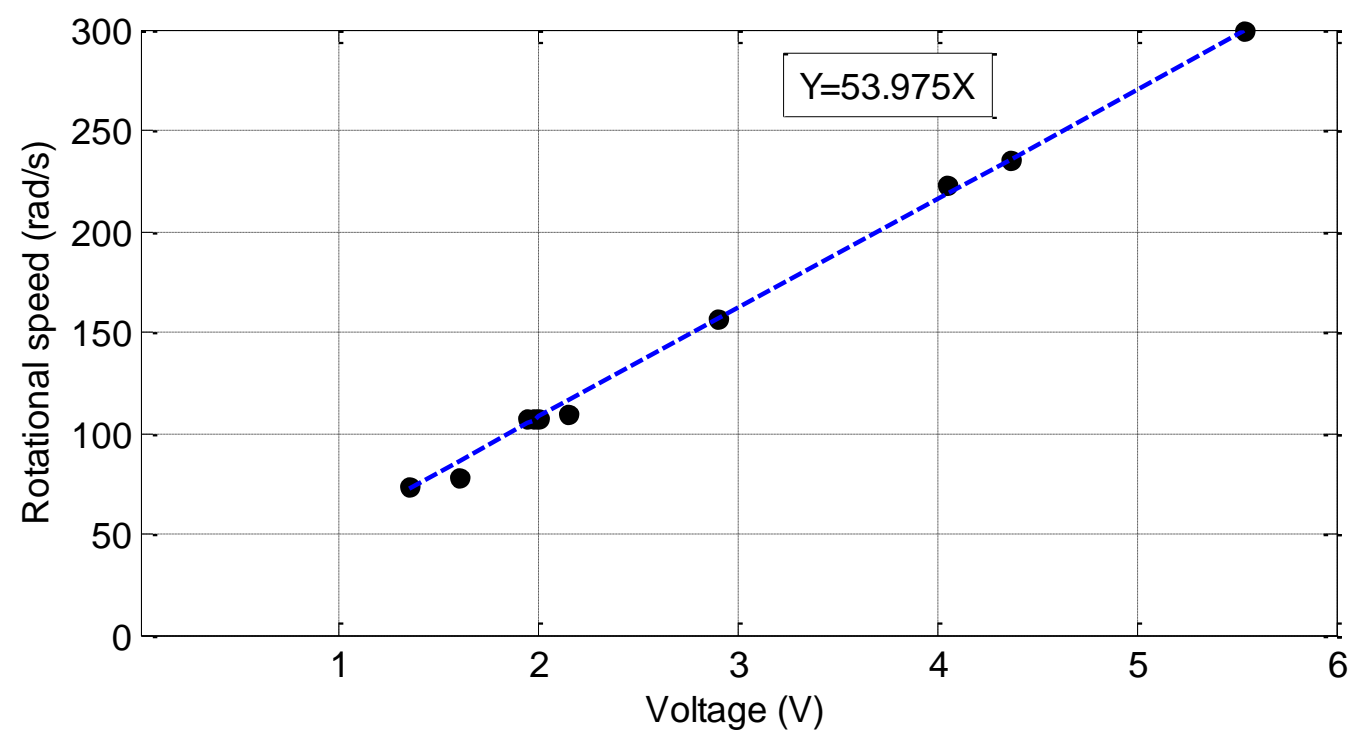

Figure 12: Rotational speed versus Voltage 


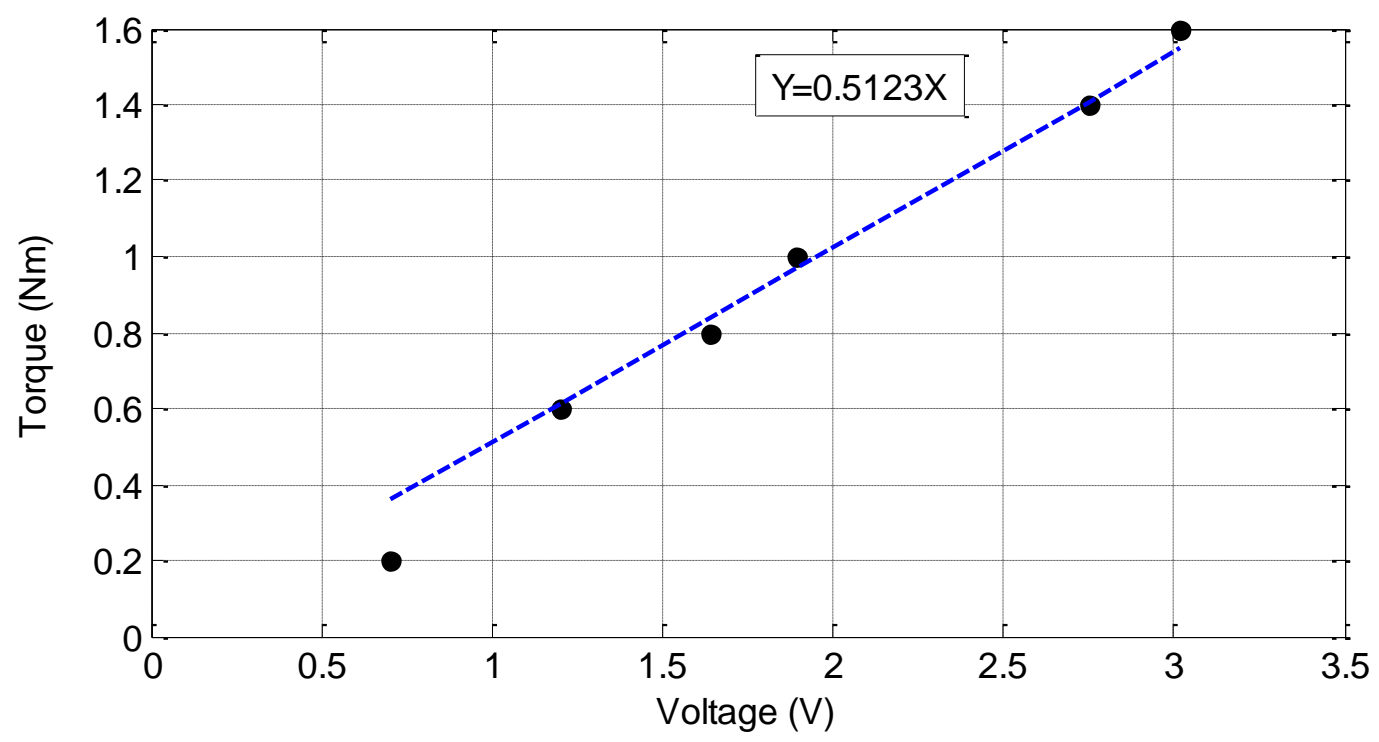

Figure 13: Torque versus Voltage

It can be noted that the measured values of speed and torque are fairly linear with the output voltage signals. The least square errors of measured data were calculated for curve fittings of each data set, which are represented by the linear relationships of rotational speeds and torques with measured voltage. These linear relationships were used to measure real time rotational speeds and torque values of the system by the output voltage signals of the "Feedback" Torque \& Speed Control module.

The rotational speed is acquired by varying the external control voltage signal according to the performance of the wind turbine for different load conditions and for particular time series wind speed data. To evaluate the plant model performance, time series rotational speed and external control voltage data of the system were collected with 0.001s sampling time through the DSP board. The input/output (I/O) unit of the dSPACE DS1103 board is a set of on-board peripherals that includes digital to analogue (DAC) channels and analogue to digital (ADC) channels [24]. Subsequently, the DSP unit of the dSPACE DS1103 board can communicate with an external analogue system by using the DAC and ADC facilities of The I/O unit.

According to the collected data, external control input voltages $\left(V_{c}\right)$ are not linear with demanded rotational speeds at dynamic condition $\left(d \omega / d t \neq 0 \& d T_{e} / d t \neq 0\right)$ and hence this characteristic cannot be represented by a linear model. Therefore a nonlinear control technique is required to implement control of the d.c. shunt motor according to the reference model. The Nonlinear Autoregressive Moving Average (NARMA) model, which was introduced by Narendra and Mukhopadhyay, can be used to represent the input and output characteristics of a nonlinear system [31]. The classical PID controller cannot be used effectively since it is based on linear system theory. To overcome this problem, a NARMA-L2 Controller was designed and implemented in real time [32] for the research presented here. An approximate NARAM-L2 model was used to represent the operation of the integrated system of the "Feedback" Torque \& Speed Control module and the d.c shunt motor. The NARMA-L2 controller transforms nonlinear system dynamics into linear dynamics by cancelling the nonlinearities and this can be simply accomplished by Neural Network model [33]. The neural network was trained 
offline in batch form by back-propagation. The measured external control input voltage $\left(V_{c}\right)$ values for each rotational speed $(\omega)$ value of the d.c shunt motor and for different load and $d \omega / d t$ conditions, which are consistent with real wind speed variations, were used for training the neural network. The Levenberg-Marquardt algorithm was used to train this network by using 40000 data sets, which were collected by using the dSPACE data acquisition system [34]. The NARMA-L2 model is represented as follows;

$$
\begin{aligned}
\omega_{r e f}(k+d)=f & {\left[\omega(k), \ldots . ., \omega(k-n+1), V_{c}(k) \ldots, V_{c}(k-m+1)\right] } \\
& +g\left[\omega(k), \ldots \omega(k-n+1,), V_{c}(k), \ldots . V_{c}(k-m+1)\right] V_{c}(k+1)
\end{aligned}
$$

Functions " $f$ " and " $g$ " are estimated by using the neural network.

Using the NARMA-L2 model, the control voltage signal can be obtained as;

$$
\begin{aligned}
& V_{c}(k+1)= \\
& \frac{\omega_{r e f}(k+d)-f\left[\omega(k), \ldots \omega(k-n+1), V_{c}(k), \ldots . V_{c}(k-n+1)\right]}{g\left[\omega(k), \ldots \omega(k-n+1), V_{c}(k), \ldots V_{c}(k-n+1)\right]}
\end{aligned}
$$

where $\omega_{\text {ref }}(k+d)$ is the reference signal to be tracked. $V_{c}(k+1)$ is the plant ("Feedback" system) input, $\omega(k)$ is the plant output.

The NARMA-L2 neural network controller shown in Figure 14, provides the control input signal $V_{c}$ to the "Feedback" Torque \& Speed Control module. In this control system, the control reference rotational speed $\left(\omega_{r e f}\right)$ is estimated by the reference model. The NARMA-L2 controller determines the control input $\left(V_{c}\right)$ by considering Tapped Delayed Values (TDV) of real time rotational speed $(\omega)$ and control input $\left(V_{c}\right)$. In this process, the output of the system $(\omega)$ follows the control reference $\left(\omega_{r e f}\right)$ [35].

The parameters for system identification are shown in Table 1.

Table 1: NARMA-L2 neural network controller system identification parameters

\begin{tabular}{|l|l|}
\hline Parameters & values \\
\hline Input range $\left(V_{c}\right)$ & {$[0,6] \mathrm{V}$} \\
\hline Sample time & $0.001 \mathrm{~s}$ \\
\hline Delayed input $(m)$ & 25 \\
\hline Delayed output $(n)$ & 25 \\
\hline Hidden layer size & 15 \\
\hline
\end{tabular}

\subsection{Digital Signal Processing (DSP) Control Techniques}

The wind turbine emulator was implemented with a DSP control \& data acquisition board. The reference model and the plant model incorporated with the NARMA-L2 model reference controller were performed in the dSPACE environment (which is linked to a computer). All control models were developed in SIMULINK and then embedded system models were rebuilt in the dSPACE environment (by using the real time workshop option in SIMULINK) for real time operation. Real time rotational 
speed and shaft torques time series data of the system should be acquired in order to estimate the wind turbine emulator control signal $V_{c}$. Therefore, "Speed-out" and "Torque-out" facilities of the "Feedback" Torque \& Speed Control module were used to get real time rotational speed and shaft torque values and these time series data were processed by the DSP board. The output signals of the "Feedback" Torque \& Speed Control module are 'noisy' and they could not be directly used to control the system. Therefore, the high frequency noise components of the signals were removed by using a low-pass digital filter, developed for this purpose by using MATLAB Digital Signal Processing tool box.

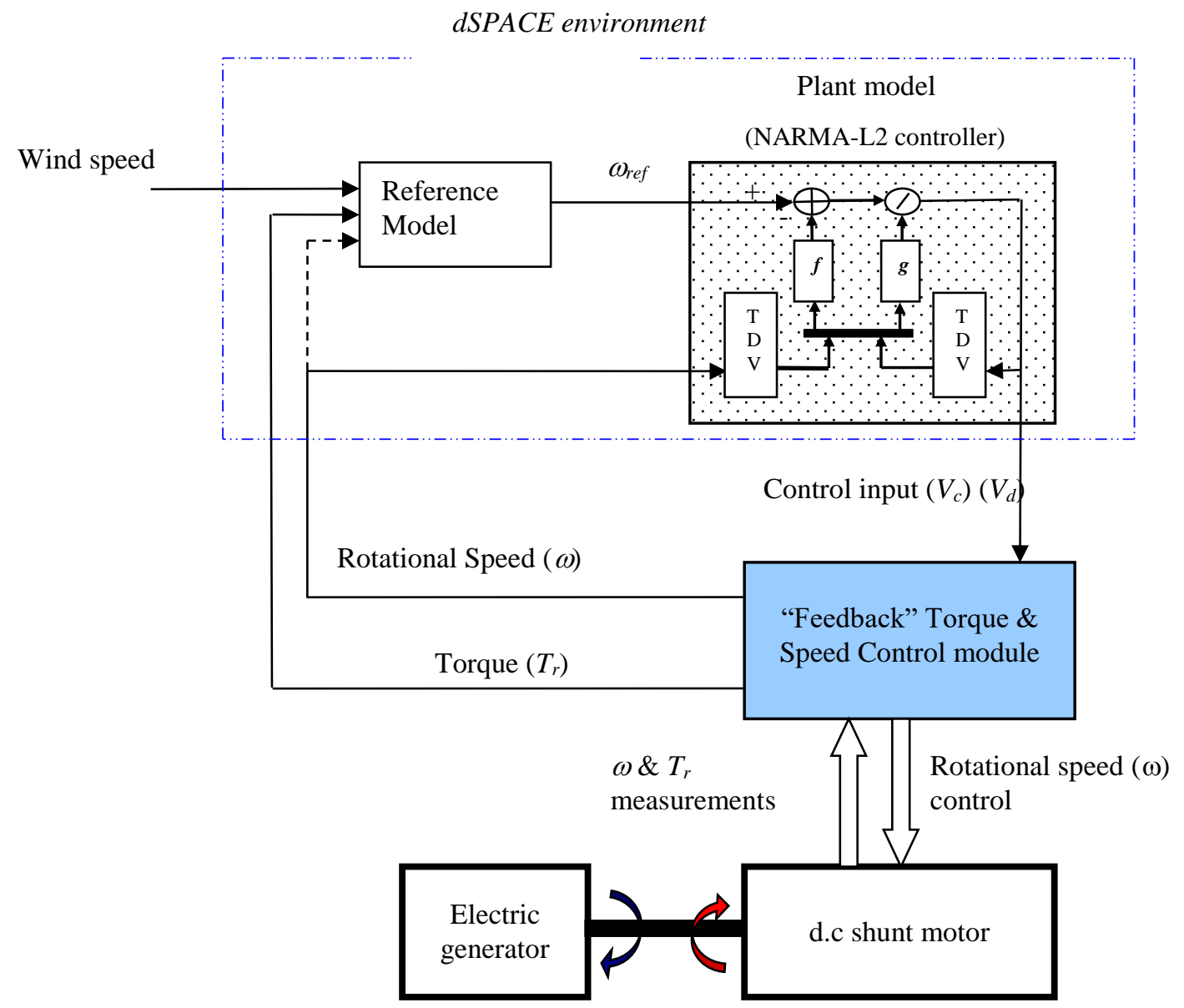

Figure 14: NARMA-L2 neural network d.c. shunt motor controller

\subsection{Validation of the Model Reference Controller}

For proper operation of the wind turbine emulator, the NARMA-L2 controller should estimate the control signal $\left(V_{c}\right)$ for controlling the system output to follow the control reference. In this control strategy, the reference model estimates the control reference signal $\left(V_{c}\right)$ according to the mathematical model of the wind rotor. To evaluate the performance of the model reference NARMA-L2 controller, the system output parameters are compared with the control reference values, which are calculated for the wind rotor mathematical model. In the proposed wind turbine emulator, the rotational speed is the control parameter, which is evaluated in accordance with the given wind speed variations and system torque values. Therefore the control error can be evaluated by the difference of the calculated control reference and the measured real value $\left(\omega_{\text {ref }}\right.$ - 
$\omega)$. The validation results are presented in Figure 15 and the validation results show that the maximum rotational speed control error is $+/-1.2 \mathrm{rad} / \mathrm{s}$.

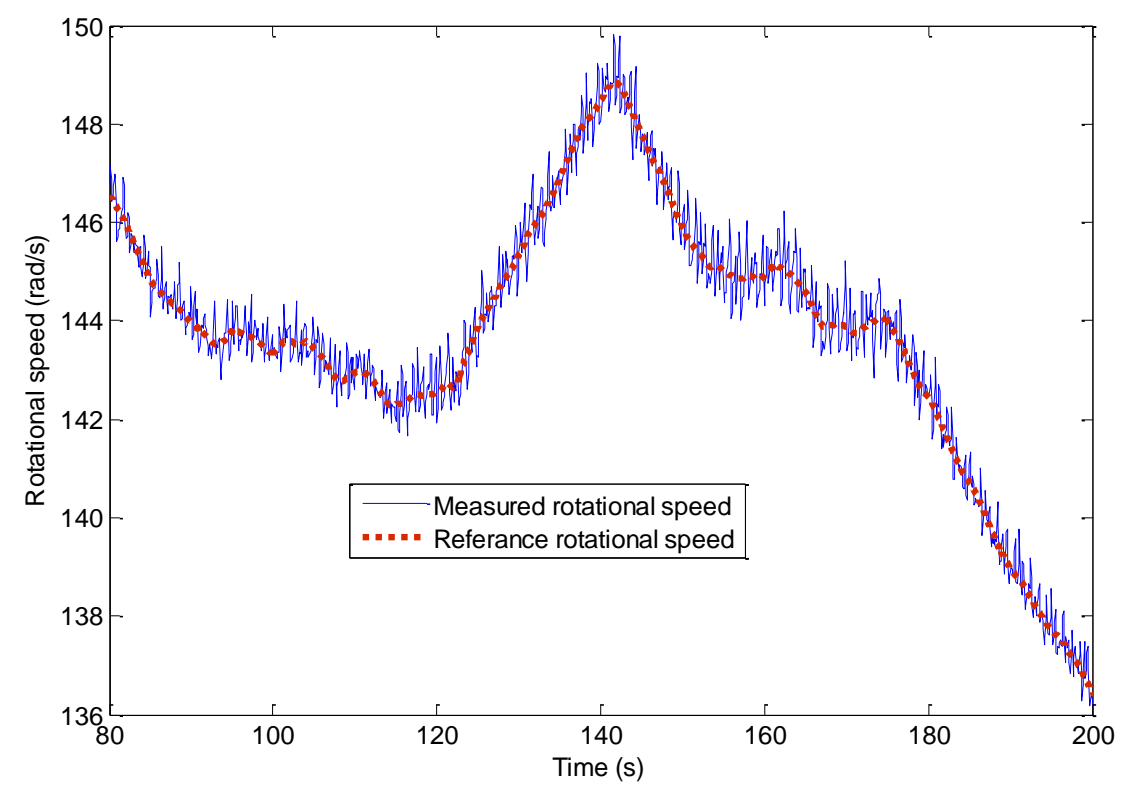

Figure 15: Validation results of the wind turbine emulator

\subsection{Test rig}

The experimental setup was based on a wind turbine emulator coupled to a three-phase permanent magnet generator. The wind turbine emulator is a prime mover (d.c. motor), which follows output torque-speed characteristics of a real wind rotor for given time series wind speed data. A load controller of the generator is implemented for maximum power point tracking of the WECS. In this experimental setup, the d.c. motor and power output of the generator were separately controlled by two independent digital control modules. The d.c. motor was controlled as a wind turbine emulator according to given time series real wind data. Measured wind speed values with 1 second logging time data were used for the test rig. Power output of the generator was controlled by considering each optimum control strategy. In this test rig, a single dSPACE control board (DS1103), which is a single-board system with real-time processor and comprehensive I/O (dSPACE Inc) [29], was utilised to simultaneously perform both d.c. motor and generator control systems. The dSPACE control board can be used with the Real-Time Interface (RTI) of the MATLAB/Simulink ${ }^{\circledR}$ block diagram environment. The wind turbine emulator/generator test rig is shown in Figure 16 The Torque \& Speed Control module was directly connected to the dSPACE I/O control board as voltage limits of the input and output signals are compatible. 


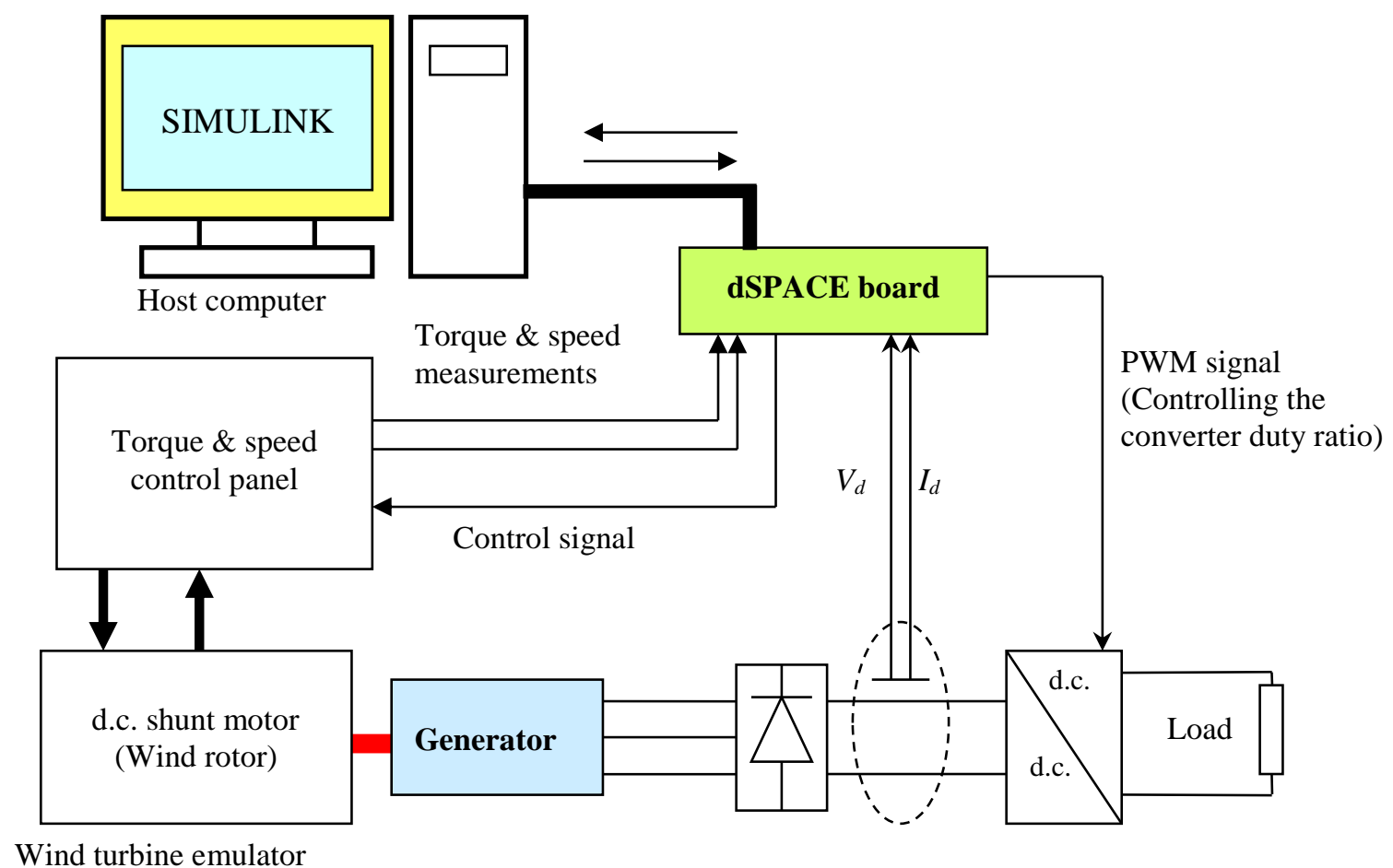

Figure 16: Test rig configuration

The three phase a.c. output of the generator was converted to d.c. by using a full wave bridge rectifier. The d.c. voltage and current values were measured by using a voltage sensor (N2772A $20 \mathrm{MHz}$ Differential probe) and a current transducer (HY5-P). These two signals were fed to the dSPACE control board by considering calibrated gain parameters of the sensors. The electrical load on the generator was controlled by varying the duty cycle ratio (PWM) of the d.c.-d.c. converter (see Figures 5 and 11) [36]. The PWM signal was generated through the dSPACE control board. The host computer was used to build the Simulink control models and linked for Real-Time Interface (RTI) with the dSPACE control board.

The wind turbine emulator specifications are provided in Table 2;

Table 2: Wind turbine emulator specifications as utilised in the test-rig

\begin{tabular}{|c|c|c|c|}
\hline \multicolumn{2}{|l|}{ Wind Rotor } & \multicolumn{2}{|l|}{ Generator } \\
\hline Parameters & values & Parameters & values \\
\hline Radius of the wind rotor $(R)$ & $0.7 \mathrm{~m}$ & Phase resistance $\left(R_{p h}\right)$ & $35.5 \Omega$ \\
\hline Number of blades & 2 & Phase inductance $\left(L_{p h}\right)$ & $0.080987 \mathrm{H}$ \\
\hline $\begin{array}{l}\text { Moment of inertia of rotating } \\
\text { parts }(J)\end{array}$ & $2 \mathrm{~kg} \cdot \mathrm{m}^{2}$ & $\begin{array}{l}k^{\prime}(\text { as described in equations } \\
(12) \text { and (13)) }\end{array}$ & 2.1 \\
\hline
\end{tabular}

\section{Experimental Results}

The wind turbine emulator was used to evaluate the effectiveness of the time series linear prediction for optimal control of wind turbines. This is necessary since it is more difficult (if not impossible) to carry out an appropriate comparative study of the performance of a real wind turbine subjected to variable wind conditions. The wind 
turbine emulator was operated with a 1 second logging time measured wind speed data to imitate real conditions with effects of momentum of inertial of the rotating part of the WECS. The effects of coning and flapping of the rotor blades are assumed to be negligible and hence were not considered in this study. Also for small scale wind turbines, the tower shadow effect is negligible [25][26] and the wind rotor is directly coupled to the generator by a short shaft. Thus the power transmission drive train configuration of WECSs is similar to the drive train of the motor-generator set used in the proposed emulator.

For comparison, the performance of each control system was evaluated for the same time series wind speed data set (same wind condition), which can be employed to the wind turbine emulator.

The DSP board-1103 was used to control the duty cycle of the d.c.- d.c. converter and therefore the loading on the generator. The loading is controlled by considering the wind speed sensor method and the power mapping control method with and without linear predictions of wind speed. Each system was emulated for measured (real) wind data. The energy extraction for each method - over 2500 seconds - are presented in Table 3. It is evident that the energy yield from a wind energy conversion system is increased by almost $5 \%$ with the use of linear prediction techniques.

Table 3: Energy extraction

\begin{tabular}{|l|c|c|}
\hline & $\begin{array}{c}\text { wind speed sensor } \\
\text { control method }(\mathrm{J})\end{array}$ & $\begin{array}{l}\text { Power mapping } \\
\text { control method }(\mathrm{J})\end{array}$ \\
\hline Extracted energy without prediction & 121478.7 & 117371.3 \\
\hline Extracted energy with prediction & 127333.9 & 121771.8 \\
\hline Increase in energy yield \% & $4.82 \%$ & $3.75 \%$ \\
\hline
\end{tabular}

\section{Conclusions}

As a consequence of inertia, the rotational speed of a wind rotor cannot be changed instantaneously. By predicting wind speeds at time-ahead time intervals, the prediction of a wind rotor rotational speed control reference facilitates system control to acquire optimal maximum power operating point. Wind speed can be predicted with reasonable accuracy based on historical time series data. Experimental tests conducted using a WECS emulator showed that energy capture of WECSs can be improved by predicting the control reference and this can increase the energy yield by almost $5 \%$.

The rotational speed of a wind rotor is controlled by varying the restoring torque of the generator $\left(T_{e}\right)$, which is proportional to the generator current $\left(I_{d}\right)$. Some physical limitations are identified to control the system in acquiring the optimal rotational speed for particular wind speed value. Even though the control reference is accurately predicted, the variation of rotational speed $(d \omega / d t)$ is limited by rating capacity of the generator current $\left(I_{d}\right)$ and due to limitations of the structural strength of the wind turbine.

The experimental results obtained in this study show that the performance of the wind sensor method is better than the power mapping wind sensorless method. This is because in the power mapping technique, it is difficult to estimate the relevant control reference at dynamic state $(d \omega / d t \neq 0)$ by the predetermined system characteristics. 
However, in practice it is difficult to accurately measure the wind speed by an anemometer installed close to the wind turbine, as the wind turbine experience different forces due to wake rotation.

\section{Acknowledgment}

The authors would like to thank Northumbria University, UK, University of Moratuwa, Sri Lanka, Dublin Institute of Technology, Ireland and National Renewable Energy Centre (currently Offshore Renewable Energy Catapult), UK for their support to this project.

\section{References}

[1] GWEC, "Global Wind Report - Annual Market Update," Global Wind Energy Council, 2015. [Online]. Available: www.gwec.net/wpcontent/uploads/vip/GWEC-Global-Wind-2015-Report_April-2016_22_04.pdf. [Accessed: 26-Oct-2016].

[2] International-Energy-Agency, "Technology Roadmap: Hydropower,” 2012. [Online]. Available:

https://www.iea.org/publications/freepublications/publication/2012_Hydropow er_Roadmap.pdf. [Accessed: 26-Oct-2016].

[3] S. M. Tripathi, A. N. Tiwari, and D. Singh, "Grid-integrated permanent magnet synchronous generator based wind energy conversion systems: A technology review," Renew. Sustain. Energy Rev., vol. 51, pp. 1288-1305, 2015.

[4] I. . Kortabarria, J. . Andreu, I. . de Alegría, J. . Jiménez, J. I. . Gárate, and E. . Robles, "A novel adaptative maximum power point tracking algorithm for small wind turbines," Renew. Energy, vol. 63, pp. 785-796, 2014.

[5] M. A. Abdullah, A. H. M. Yatim, C. W. Tan, and R. Saidur, "A review of maximum power point tracking algorithms for wind energy systems.," Elsevier, vol. 16, pp. 3220-3227, 2012.

[6] M. Narayana, G. A. Putrus, M. Jovanovic, P. S. Leung, and S. McDonald, "Generic maximum power point tracking controller for small-scale wind turbines," Renew. Energy, vol. 44, pp. 72-79, Aug. 2012.

[7] F. Delfino, F. Pampararo, R. Procopio, and M. Rossi, “A Feedback Linearization Control Scheme for the Integration of Wind Energy Conversion Systems into Distribution Grids," Syst. Journal, ..., vol. 6, no. 1, pp. 85-93, 2012.

[8] H.-B. Zhang, J. Fletcher, N. Greeves, S. J. Finney, and B. W. Williams, "Onepower-point operation for variable speed wind/tidal stream turbines with synchronous generators," IET Renew. Power Gener., vol. 5, no. 1, p. 99, 2011.

[9] T. G. Barbounis and J. B. Theocharis, "Locally recurrent neural networks for wind speed prediction using spatial correlation," Inf. Sci. (Ny)., vol. 177, no. 24, pp. 5775-5797, 2007.

[10] M. Lei, L. Shiyan, J. Chuanwen, L. Hongling, and Z. Yan, "A review on the forecasting of wind speed and generated power," Renew. Sustain. Energy Rev., vol. 13, no. 4, pp. 915-920, 2009.

[11] E. Cadenas and W. Rivera, "Wind speed forecasting in the South Coast of Oaxaca, M??xico," Renew. Energy, vol. 32, no. 12, pp. 2116-2128, 2007.

[12] M. A. Mohandes, S. Rehman, and T. O. Halawani, "A neural networks approach for wind speed prediction," Renew. Energy, vol. 13, no. 3, pp. 345- 
354, 1998.

[13] S. Bououden, M. Chadli, S. Filali, and A. El Hajjaji, "Fuzzy model based multivariable predictive control of a variable speed wind turbine: LMI approach," Renew. Energy, vol. 37, no. 1, pp. 434-439, 2012.

[14] G. Sideratos and N. D. Hatziargyriou, "An Advanced Statistical Method for Wind Power Forecasting," vol. 22, no. 1, pp. 258-265, 2007.

[15] S. Rogers, Adaptive filter theory, vol. 4. Englewood Cliffs, NJ: Prentice Hall, 1996.

[16] M. Tohidian, A. Esmaili, R. A. Naghizadeh, S. H. H. Sadeghi, A. Nasiri, and A. M. Reza, "Use of adaptive linear algorithms for very short-term prediction of wind turbine power output," IECON 2012 - 38th Annual Conference on IEEE Industrial Electronics Society. pp. 1162-1165, 2012.

[17] T. Burton, N. Jenkins, D. Sharpe, and E. Bossanyi, Wind Energy Handbook, 2nd Edition. 2011.

[18] F. V. P. Robinson, Power electronics converters, applications and design, 3rd ed., vol. 28, no. 1. John Wiley and Sons, 1997.

[19] M. Arifujjaman, M. T. Iqbal, and J. E. Quaicoe, "Energy capture by a small wind-energy conversion system," Appl. Energy, vol. 85, no. 1, pp. 41-51, Jan. 2008.

[20] Y. Shynkevich, T. M. McGinnity, S. Coleman, Y. Li, and A. Belatreche, "Forecasting stock price directional movements using technical indicators: Investigating window size effects on one-step-ahead forecasting," IEEE/IAFE Conf. Comput. Intell. Financ. Eng. Proc., pp. 341-348, 2014.

[21] J. A. Baroudi, V. Dinavahi, and A. M. Knight, "A review of power converter topologies for wind generators," Renew. Energy, vol. 32, no. 14, pp. 23692385, Nov. 2007.

[22] J. G. Ziegler and N. B. Nichols, "Optimum settings for automatic controllers," InTech, vol. 42, no. 6, pp. 94-100, 1995.

[23] K. Tan and S. Islam, "Optimum control strategies in energy conversion of PMSG wind turbine system without mechanical sensors," IEEE Trans. Energy Convers., vol. 19, no. 2, pp. 392-399, 2004.

[24] dSPACE, "DS1103 PPC Controller Board RTI Reference," 2010. [Online]. Available: https://www.dspace.com/shared/data/pdf/2014/DS1103.pdf. [Accessed: 06-Dec-2016].

[25] N. Stannard and J. R. Bumby, "Performance aspects of mains connected smallscale wind turbines," Gener. Transm. Distrib. IET, vol. 1, no. 2, p. 324, 2007.

[26] S. Kumsup and C. Tarasantisuk, "Real-time wind turbine emulator for testing wind energy conversion systems," 2010 IEEE International Energy Conference. pp. 7-9, 2010.

[27] Feedback_Instruments, "Electrical Machines Core System," 2016. [Online]. Available: http://www.feedback-

instruments.com/products/education/electrical_power_machines/electrical_mac hines_core_system. [Accessed: 06-Dec-2016].

[28] K. S. Narendra and K. Parthasarthy, "Identification and control of dynamical systems using neural networks," in IEEE Trans. on Neural Networks, 1990, vol. 1, no. 1, pp. 4-27.

[29] H. Michalska, "Model reference control-system design for norm-uncertain plants," Int. J. Control, pp. 439-452, 1987.

[30] W. A. A. M. Bierbooms, "A comparison between unsteady aerodynamic models," J. Wind Eng. Ind. Aerodyn., vol. 39, no. 1, pp. 23-33, 1992. 
[31] K. S. Narendra and S. Mukhopadhyay, "Adaptive control using neural networks and approximate models," IEEE Trans. Neural Networks, vol. 8, no. 3, pp. 475-485, 1997.

[32] S. S. Mokri, H. Husain, W. Martono, A. Shafie, U. K. M. Bangi, and S. De, "Real Time Implementation of NARMA-L2 Control of a Single Link Manipulator Faculty of Engineering, Kulliyah of Engineering, International Islamic University of Malaysia, 50728, Kuala Lumpur, Malaysia,” Am. J. Appl., vol. 5, no. 12, pp. 1642-1649, 2008.

[33] A. Pukrittayakamee, O. De Jesus, and M. T. Hagan, "Smoothing the Control Action for NARMA-L2 Controllers," in 45th Midwest Symposium on Circuits and Systems, 2002, vol. 3, pp. 37-40.

[34] D. W. Marquardt, "An Algorithm for Least-Squares Estimation of Nonlinear Parameters," J. Soc. Ind. Appl. Math., vol. 11, no. 2, pp. 431-441, 1963.

[35] Wahyudi, S. S. Mokri, and A. A. Shafie, "Real time implementation of NARMA L2 feedback linearization and smoothed NARMA L2 controls of a single link manipulator," 2008 International Conference on Computer and Communication Engineering. pp. 691-697, 2008.

[36] G. Hua and Y. Geng, "A novel control strategy of MPPT taking dynamics of wind turbine into account," in PESC Record - IEEE Annual Power Electronics Specialists Conference, 2006, p. 1-6. 